\title{
Comunicação
}

[Communication]

\section{Spalangia nigroaenea Curtis, 1839 (Hymenoptera: Pteromalidae) como inimigo natural de dípteros coletados em fezes bovinas no sul do Estado de Goiás}

[Spalangia nigroaenea Curtis, 1839 (Hymenoptera: Pteromalidae) as natural enemy of muscoid dipterous collected in cattle dung in south of Goiás State, Brazil]

\section{C.H. Marchiori}

Instituto Luterano de Ensino Superior de Itumbiara-ULBRA

Caixa Postal 23-T

75500-000 - Itumbiara, GO

\begin{abstract}
Os dípteros caliptrados constituem modelo adequado para o estudo de sinantropia, não apenas pela sua importância ecológica, mas também pelo seu aspecto médico-sanitário, como vetores mecânicos de patógenos tais como: cistos de amebas, ovos de helmintos, bactérias enteropatogências, vírus e fungos (Greenberg, 1971). Como possibilidade de controle desses dípteros, podem ser utilizados os parasitóides, agentes responsáveis pela redução de populações de moscas.
\end{abstract}

A família Pteromalidae (Hymenoptera, Chalcidoidea) inclui grande número de espécies parasitóides, muitas das quais têm importância no controle biológico de muscóides sinantrópicos (Rueda e Axtell, 1985). Na subfamília Spalanginae (Hymenoptera: Chalcidoidea: Pteromalidae), há 12 espécies na região neotropical.

As espécies de Spalangia Latrielle, 1805 são primariamente parasitóides de moscas das famílias Muscidae, Calliphoridae, Sarcophagidae, Drosophilidae e Chloropidae em várias partes do mundo, sendo possível seu uso no controle biológico (Boucek, 1963). Muitas espécies conhecidas desenvolvem-se em hospedeiros que vivem em fezes, carne em decomposição e tecidos de plantas. As espécies de Spalangia, predominantemente associadas a esterco bovino, são parasitóides de pupários. Muitos dados obtidos de sua biologia mostram que são hospedeiros da Musca domestica L. (Diptera: Muscidae (Rueda e Axtell, 1985).

O objetivo deste trabalho foi verificar os principais hospedeiros de Spalangia nigroaenea encontrados em fezes bovinas no sul de Goiás.

O experimento foi realizado na Fazenda Boa Vista em Cachoeira Dourada (18²9'S e $\left.49^{\circ} 28^{\prime} \mathrm{W}\right), \mathrm{GO}$, e na Fazenda da Faculdade de Agronomia em Itumbiara (18 $25^{\prime} \mathrm{S}$ e $\left.49^{\circ} 13^{\prime} \mathrm{W}\right)$, GO. Fezes frescas, marcadas imediatamente após sua emissão em pastagens de braquiária (Brachiaria brizantha) (Hochst ex. A. Rich), com auxílio de estacas de madeira branca $(30 \mathrm{~cm}$ de altura e $5 \mathrm{~cm}$ de espessura), para determinação precisa do tempo entre a emissão e a coleta, permaneceram no campo por 15 dias. Sete amostras foram colhidas e levadas ao laboratório para a extração das pupas pelo método da flutuação. Juntamente com as fezes, foram retirados $5 \mathrm{~cm}$ do substrato situado abaixo do local de deposição no solo. As pupas foram retiradas com o auxílio de uma peneira, contadas e individualizadas em cápsulas de gelatina (número 00) até a emergência das moscas e/ou dos parasitóides. Os parasitóides e as moscas emergidos, identificados com auxílio de um microscópio esteroscópio, foram conservados em álcool $70 \%$.

Entre janeiro de 1998 e fevereiro de 2001, 53 espécimes de Spalangia nigroaenea Curtis, 1839

Recebido em 22 de março de 2004

Aceito em 20 de julho de 2005

E-mail: pesquisa.itb@ulbra.br 
(Hymenoptera: Pteromalidae) foram coletados em 7203 pupas de dípteros (Tab. 1). A porcentagem de parasitismo foi de $0,74 \%$. Spalangia nigroaenea apresentou maior porcentagem de parasitismo em pupas de Brontaea quadristigma (Thomson) (Diptera: Muscidae) com 2,5\%. No Brasil, S. nigroaenea foi coletada nos estados de Mato Grosso, São Paulo e Minas Gerais em M. domestica L. $e$ Stomoxys calcitrans (L.) (Diptera: Muscidae), provenientes de esterco bovino (Silveira et al., 1989). Nos Estados Unidos, S. nigroaenea foi encontrada em $14,0 \%$ de pupas de Haematobia irritans (L.) (Diptera: Muscidae) no estado do Mississippi (Combs e Hoelscher, 1969), 3,0\% em M. domestica em fazendas de New York (Smith e Rutz, 1991) e 0,70\% em S. calcitrans, em fazendas do Missouri (Smith et al., 1987).

Os dípteros muscóides têm relevância em saúde pública, como potenciais vetores mecânicos de agentes etiólogicos (Mendes e Linhares, 1993).

Palavras-chave: dípteros muscóides, moscas, parasitóides, gado, fezes

Tabela 1. Prevalência de parasitismo de Spalangia nigroaenea obtidos em fezes bovinas em diferentes hospedeiros no Sul do Estado de Goiás, de janeiro de 1998 a fevereiro de 2001

\begin{tabular}{lccc}
\hline Hospedeiro (n. ${ }^{\circ}$ de pupários) & Freqüência & No. de pupas parasitadas $^{\text {. }}$ & Parasitismo (\%) \\
\hline Brontaea quadristigma (720) & 18 & 18 & 2,50 \\
Brontaea debilis (452) & 4 & 4 & 0,88 \\
Cyrtoneurina pararescita (2664) & 12 & 12 & 0,45 \\
Musca domestica (227) & 3 & 3 & 1,32 \\
Palaeosepsis spp. (307) & 3 & 3 & 0,98 \\
Sarcophagula occidua (2833) & 13 & 13 & 0,46 \\
\hline
\end{tabular}

\begin{abstract}
From January 1998 to February 2001, 53 specimens of Spalangia nigroaenea Curtis, 1839 (Hymenoptera: Pteromalidae) were collected in 7,203 pupae of flies in cattle dung in Cachoeira Dourada and Itumbiara, GO, Brazil. The samples were collected and taken to the laboratory for pupae extraction by water flotation technique. The pupae were individually placed in transparent gelatin capsules until the emergence of the adult flies or their parasitoids. The percentage of parasitism was $0.74 \%$.
\end{abstract}

Keywords: muscoid dipterous, fly, parasitoid, cattle, manure, Brazil

\section{REFERÊNCIAS BIBLIOGRÁFICAS}

BOUCEK, Z.A. Taxonomic study in Spalangia Latr. (Hymenoptera: Chalcidoidea). Acta Ent. Mus. Nat. Pragae, v.35, p.429-512, 1963.

COMBS Jr., R.L.; HOELSCHER, C.E. Hymenopterous pupal parasitoids found associated with horn fly in Northeast Mississippi. J. Econ. Entomol., v.62, p.1234-1235, 1969.

GREENBERG, B. Flies and disease: ecology, classification and biotic association. New Jersey: Princeton University, 1971. v.1. 856p.

MENDES, J.; LINHARES A.X. Atratividade por iscas, sazonalidade e desenvolvimento ovariano em várias espécies de Muscidae (Diptera). Rev. Bras. Entomol., v.37, p.289-297, 1993.
RUEDA, L.M.; AXTELL, R.C. Guide to common species of pupal parasites (Hymenoptera: Pteromalidae) of the house fly and other muscoid flies associated with poultry and livestock manure. Tech. Bull. North Carolina Agric. Res. Serv., n.128, p.1-88, 1985.

SILVEIRA, G.A.R.; MADEIRA, N.G.; AZEREDOESPIN, A.M.L. et al. Levantamento de microhimenóptera parasitóides de dípteros de importância médico-veterinária no Brasil. Mem. Inst. Oswaldo Cruz, v.84, p.505-510, 1989.

SMITH, J.P.; HALL, R.D.; THOMAS, G.D. Field parasitism of the stable fly (Diptera: Muscidae). Ann. Entomol. Soc. Am., v.80, p.391-397, 1987.

SMITH, L.; RUTZ, D.A. Seasonal and relative abundance of hymenopterous parasitoids attacking house fly pupae at dairy farms in Central New York. Environ. Entomol., v.20, p.661-668, 1991. 